\title{
A questão Quilombola e o CAMPo do DiReito
}

\author{
Amanda Lacerda JORGE \\ André Augusto Pereira BRANDÁO**
}

\begin{abstract}
RESUMO: A questão quilombola vem se constituindo desde 1988 no Brasil, a partir dos agenciamentos que culminaram no artigo 68 do Ato das Disposições Constitucionais Transitórias (ADCT). Por meio deste dispositivo ficou garantido o direito à propriedade da terra para este grupo. Mas, a partir deste ponto abremse complexas janelas de interpretação que se voltam para a regulamentação do texto constitucional. Neste artigo nos apropriamos da noção de campo, tal como definida na obra de Bourdieu, para pensar a inserção do direito na complexa disputa discursiva em torno da definição socialmente legítima de quem seriam os quilombolas. Atravessamos este debate tomando como foco principal o litígio no âmbito do Supremo Tribunal Federal (STF) acerca da validade de conceitos e caracterizações sobre quem seriam os quilombolas e seus territórios.
\end{abstract}

PALAVRAS-CHAVE: Comunidades quilombolas. Campo do direito. Supremo Tribunal Federal (STF).

\section{1 - Introdução}

Neste artigo nos apropriamos da noção de campo, tal como definida em Bourdieu (2003) para pensar a inserção do direito na complexa disputa discursiva em torno da definição socialmente legítima ${ }^{1}$ de quem são os quilombolas e quais os

\footnotetext{
UFF- Universidade Federal Fluminense. Estudos Pós-Graduados em Política Social/Serviço Social. Niterói - RJ - Brasil. 24210-201 - amandalacerda@id.uff.br. https://orcid.org/0000-0003-3005-9233.

* UFF- Universidade Federal Fluminense. Estudos Pós-Graduados em Política Social/Serviço Social. Niterói - RJ - Brasil. 24210-201 - andre_brandão@id.uff.br. https://orcid.org/0000-0002-9245-0273.

1 Utilizamos os termos legítimo(a) e legitimidade no sentido weberiano, ou seja, como o que é reconhecido por aqueles que compõem determinado grupo ou sociedade. Este uso aparece com clareza na definição dos tipos de dominação (WEBER, 1994).
} 
seus direitos. Nos estudos de Anjos (2005, p. 89) o arcabouço teórico bourdieusiano foi pensado a fim de analisar a construção de categorias a partir de uma série de enunciações públicas que converteram o conceito de territórios negros na categoria comunidades remanescentes de quilombos, como elemento jurídico e político para tornar este grupo politicamente pensável para os atuais parâmetros de políticas públicas. Ou seja, o autor neste trabalho apresenta a trajetória discursiva dos principais agentes responsáveis pela formatação da emergência das comunidades quilombolas como tema público no estado do Rio Grande do Sul.

Partirmos desta perspectiva, ao concordamos que o conceito de campo na teoria de Pierre Bourdieu (2003), enriquece a própria ideia de sociedade. Como nos aponta este teórico: campos correspondem a universos sociais com algum grau de autonomia, que constituem espaços de poder, compostos por relações de força, interesses, estratégias de mudança ou manutenção. Cada grupo ou sujeito que deles participam, quer ver prevalecer a sua interpretação, com imposição de princípios legítimos de visão e de divisão (BOURDIEU, 2003). Do ponto de vista analítico, um campo equivale a uma rede de relações objetivas, na qual os agentes envolvidos disputam o monopólio da autoridade legitima dentro de seus limites. A própria possibilidade de "entrar no campo", depende da posse de "uma configuração particular de propriedades" (BOURDIEU e WACQUANT, 1992, p. 83 - tradução livre).

Dessa forma, o objetivo aqui é refletir sobre este arcabouço conceitual para buscarmos maiores reflexões sobre o campo do direito e a sua participação na construção da questão quilombola. Este campo segundo Bourdieu (2003), seria o lugar de agentes com competência técnica, socialmente legitimada para atuar como mandatários autorizados de uma coletividade, com a função de resolver conflitos e proceder às negociações no mundo social. A interpretação de textos jurídicos, feita pelos agentes autorizados, possui um caráter plural e, por isso, este contexto apresenta um "jogo de lutas, pois a leitura é uma maneira de apropriação da força simbólica que nele se encontra em estado potencial" (BOURDIEU, 2003, p. 213). Além disso, o campo do direito consagra a visão do Estado sobre a ordem social, com um discurso produtor de efeitos, porque o poder judicial pode construir sujeitos de direitos. Sendo assim, a verdade anunciada pelos arautos deste campo pertence aos atos de nomeação ou instituição representando a palavra pública (BOURDIEU, 2003).

Atravessaremos este debate seguindo dois caminhos. O primeiro analisa os decretos através dos quais o Estado promoveu a regulamentação legal das demandas por direitos territoriais dos quilombolas. O segundo toma como objeto as disputas interpretativas acerca destes direitos no âmbito do Supremo Tribunal Federal (STF), no julgamento da Ação Direta de Inconstitucionalidade - ADI nº 3.239/2004 
que chegou ao fim no ano de 2018. Mas antes, será necessário mostrar como foi engendrada a questão quilombola.

\section{2 - Como se formou a questão quilombola?}

A questão quilombola, corresponde ao conjunto das disputas de significados e de perspectivas de nomeação do que seria este grupo, e de quais seriam seus direitos. Tal questão, não existia antes do próprio artigo 68 do Ato das Disposições Constitucionais Transitórias (ADCT), por meio do qual a Constituição indica o direito à propriedade da terra para os grupos sociais que se enquadrassem na origem quilombola. Tal artigo traz a redação: "Aos remanescentes das comunidades dos quilombos que estejam ocupando suas terras é reconhecida a propriedade definitiva, devendo o Estado emitir-lhes os títulos respectivos", da qual derivou um intenso debate sobre os limites e possibilidades de operacionalização desse dispositivo, dado o que foi considerada a imprecisão do artigo. As primeiras interpretações do artigo 68, realizadas pelo Estado foram mais restritivas, nelas a definição de quilombola associava-se às fugas de escravos no período colonial.

Figueiredo (2008) argumenta que é possível identificar uma bipartição ${ }^{2}$ do Artigo 68 do ADCT entre aspectos culturais e agrários, na medida em que estão indicados o reconhecimento da diversidade cultural brasileira por um lado e por outro, elementos distributivos de natureza fundiária. Por sobre estes dois elementos, paira a busca pela reparação de injustiças e desigualdades raciais. Não por acaso, foram membros do Congresso Nacional ligados aos movimentos sociais negros urbanos que propuseram o que viria a se tornar o Artigo 68 do ADCT (OLIVEIRA, 2009).

Este formato interpretativo foi questionado, principalmente no campo das ciências sociais brasileiras (especialmente da antropologia). A leitura do artigo 68 que tinha origem nessa crítica buscava ampliar as possibilidades de inclusão de comunidades como beneficiárias do dispositivo, por meio da criação de uma nova chave discursiva. $\mathrm{O}$ elemento fundamental consistia em afirmar a não vinculação entre o direito à terra dos quilombolas e um passado que remontava à escravidão. $\mathrm{O}$ remanescente de quilombo seria menos um produto da história e mais o resultado de engajamentos étnicos e identitários, que de forma dinâmica, estão se formando ainda no tempo presente.

Cientistas sociais situados nas universidades brasileiras, construindo um discurso especializado trabalharam no sentido de estabelecer uma interpretação

\footnotetext{
2 Esta bipartição pode ser analisada a partir do debate nascido, em meados dos anos 1990, em torno do binômio reconhecimento e redistribuição, discutido por teóricos como Axel Honneth (2007), Charles Taylor (1994) e Nancy Fraser (2010).
} 
capaz de alargar a compreensão do texto constitucional. Lançando mão do texto seminal de Barth (2000), a Associação Brasileira de Antropologia (ABA) divulgou em outubro de 1994 o Documento do Grupo de Trabalho sobre Comunidades Negras Rurais ${ }^{3}$ no qual define um significado para a nomeação contida no artigo 68: "Remanescente de quilombo, é utilizado pelos grupos para designar um legado, uma herança cultural e material que lhes confere uma referência presencial no sentimento de ser e pertencer a um lugar e a um grupo específico". (ABA, 1994, n.p.).

Ao receber este discurso, parte das comunidades anteriormente pensadas como negras rurais passariam a acionar a identidade quilombola, que até há pouco tempo elas próprias desconheciam. Desde então, o campo das ciências sociais se refere a tais grupos a partir da noção de etnicidade (BARTH, 2000). Os quilombolas emergiriam dos processos de diferenciação entre grupos que estão em interação. Em tais processos, são elaboradas classificações e autoclassificações que definem fronteiras sociais e simbólicas. A categoria quilombola é desencaixada de uma chave histórica (como resquícios do escravismo), ou biologicamente definida (através de elementos fenotípicos), para ser reconhecida a partir de um processo de mobilização étnica.

\section{3 - A regulamentação do artigo 68 do ADCT}

O primeiro esforço de regulamentação do artigo 68 não caminhou na direção que apontava para o alargamento do conceito. O governo de Fernando Henrique Cardoso (FHC), apoiado por forças políticas vinculadas ao capital agrário, vai limitar ao máximo a abrangência social da interpretação do artigo. Assim, o Decreto $\mathrm{n}^{\mathrm{o}} 3.912 / 2001$ (BRASIL, 2001, n.p.), indica que somente seria reconhecida a propriedade quilombola sobre terras que "eram ocupadas por quilombos em 1888" e "estavam ocupadas por remanescentes das comunidades dos quilombos em 05 de outubro de 1988". Tal interpretação foi considerada um retrocesso por aqueles que vinham se mobilizando a partir da releitura do conceito de quilombo.

O ano de 2003 marca a chegada ao poder, de um partido que acumulava certo grau de aproximação com os movimentos sociais. Neste contexto é emitido o

\footnotetext{
3 Trata-se de um documento amplamente citado em artigos e outros trabalhos (ARRUTI, 2006; O'DWYER, 2002). É um documento seminal e histórico que marca o discurso antropológico, encorpado por novos elementos, que dá o pontapé inicial para o processo de etnogênese quilombola, mas, também reforça o posicionamento do grupo quilombola como categoria jurídica, e como sujeito de direito frente ao Estado. Criava-se neste momento, a ideia de que as comunidades quilombolas seriam um grupo étnico, identitário, coletivamente diferenciado e tradicional - diferente, de uma reminiscência histórica, datada através de uma certa cronologia. AABA, como associação científica que afirma lutar em defesa das minorias étnicas desde a década de 1950, buscou definir quem seriam os quilombolas do tempo presente. O objetivo era fazer valer o direito a efetivação do Artigo 68 do ADCT e ao mesmo tempo delimitar as formas que deveriam ser utilizadas para classificar o que seria considerado um quilombo ou quem seriam os quilombolas.
} 
Decreto $n^{\circ} 4.887 / 2003$ (revogando o $n^{\circ} 3.912 / 2001$ ), que traz mudanças importantes na regulamentação do que seriam os quilombos e como seria atestada a sua existência:

Art. 2 Consideram-se remanescentes das comunidades dos quilombos, para os fins deste Decreto, os grupos étnico-raciais, segundo critérios de autoatribuição, com trajetória histórica própria, dotados de relações territoriais específicas, com presunção de ancestralidade negra relacionada com a resistência à opressão histórica sofrida.

$\S 1^{\circ}$ Para os fins deste Decreto, a caracterização dos remanescentes das comunidades dos quilombos será atestada mediante autodefinição da própria comunidade.

$\S 2^{\circ}$ São terras ocupadas por remanescentes das comunidades dos quilombos as utilizadas para a garantia de sua reprodução física, social, econômica e cultural (BRASIL, 2003).

Como vemos, o Decreto 4.887/2003 incorpora a definição proposta pelos antropólogos já em 1994, que apontava as comunidades quilombolas como grupos étnicos e promove, portanto, uma dupla ampliação - seja no rol de possíveis comunidades beneficiadas, seja no montante de terras a serem tituladas. No entanto, esse movimento vai gerar uma pronta resposta por parte daqueles que desde 1988, vinham buscando legitimar uma leitura mais restrita do dispositivo constitucional.

Em junho de 2004 o Decreto $n^{\circ}$ 4.887/2003 foi alvo de uma Ação Direta de Inconstitucionalidade (ADI) ${ }^{4}$, movida junto ao Supremo Tribunal Federal (STF), pelo então Partido da Frente Liberal (PFL), atual Democratas (DEM). Tem início um embate fundamental entre duas interpretações do artigo 68 no cerne do campo do direito.

\section{4 - A batalha no Supremo Tribunal Federal (STF)}

Neste artigo, discutimos os resultados da análise de uma parte dos autos da ação. Assim, nos concentramos na Petição Inicial que dá início à $\mathrm{ADI}$ n $^{\circ}$ 3.239/2004 e nos dois votos, respectivamente dos Ministros Cezar Peluso e Rosa Weber, até o momento emitidos no julgamento.

\footnotetext{
4 AADI se insere no panorama jurídico brasileiro no âmbito do controle concentrado de constitucionalidade e tem por finalidade declarar que uma lei ou parte dela é inconstitucional.
} 


\section{1 - A Petição inicial do Partido da Frente Liberal (PFL)}

A Petição inicial aponta que a matéria regulada deveria ser alvo de lei, discutida e votada no Congresso. Este argumento se baseia nos limites impostos pelo artigo $\mathrm{n}^{\circ} .84$ da Constituição Federal de 1988, que define o que "compete privadamente ao Presidente da República". O Decreto carregaria um vício de origem, advindo do "uso indevido da via regulamentar" (BRASIL, 2004, p. 5).

No que tange ao mérito, a petição ancorada em interpretação cronológica, intui que seria raro encontrar atualmente estes grupos. Portanto, garantir a possibilidade de que as comunidades se auto definissem como quilombolas equivaleria a substituir uma definição histórica, por uma "mera manifestação de vontade do interessado" (BRASIL, 2004, p. 8).

Na perspectiva dos autores da Petição, as comunidades quilombolas seriam aquelas "formadas por escravos fugidos, ao tempo da escravidão no país" (BRASIL, 2004, p. 10). Deixar de lado a comprovação, geraria uma ilegalidade, que corresponderia a reconhecer o direito a mais pessoas do que aquelas efetivamente beneficiadas pelo dispositivo.

A Petição argui ainda, a inconstitucionalidade da forma como o Decreto prevê a delimitação das áreas que seriam tituladas, na medida em que este indica que sejam levados em consideração "critérios de territorialidade indicados pelos remanescentes das comunidades dos quilombos". Utilizando um formato normativo cronológico, a Petição deduz que o artigo 68 estaria se referindo às áreas onde seria possível constatar a "localização efetiva de um quilombo" (BRASIL, 2004, p. 11), ou seja, onde as moradias que o compunham estavam construídas.

\section{2 - O voto do relator}

Em abril de 2012 teve início no plenário do STF o julgamento da ADI ${ }^{\circ}$ 3.239/2004. Os julgamentos realizados naquela instância seguem o mesmo parâmetro, ou seja, em primeiro lugar o ministro relator do processo profere seu voto. Este voto já inicia acolhendo a ADI, pelo fato do Decreto no 4.887/2003 ser "uma normativa autônoma" (BRASIL, 2012, p.6), passível de sofrer tal ação, posto que carregaria uma "inconstitucionalidade formal" (BRASIL, 2012, p.7). Neste ponto o relator cita a manifestação da Confederação da Agricultura e Pecuária do Brasil, admitida como "amicus curiae", que apresentou parecer redigido por um ex-ministro do STF, Ilmar Galvão.

Segundo o ex-ministro, a prova cabal de que o artigo 68 não pode ficar à mercê de interpretações do Executivo Federal, está no fato de que os dois últimos Decretos, $n^{\circ} 3.912 / 2001$ e n 4.887/2003, efetivaram sua regulamentação, definiam 
tanto os "remanescentes", quanto as "suas terras" de forma diferente (BRASIL, 2012, p. 7).

O ministro também identifica inconstitucionalidade material no Decreto. Mais uma vez, Peluso cita uma manifestação de "amicus curiae", desta vez da Confederação Nacional da Industria, redigida por outro ex-ministro do STF, Carlos Velloso, para afirmar que o conteúdo do Decreto $n^{\circ} 4.887 / 2003$ é ofensivo à Constituição pois utilizaria interpretações do artigo 68 do ADCT que baseadas em conceitos que denomina metajurídicos. Ou seja, o alicerce em categorias da antropologia que justificariam a forma como o Decreto caracteriza os remanescentes, bem como suas terras, seria do campo da "lege ferenda", isto é, de uma lei ainda a ser escrita. Este formato destoaria da "lege lata", a lei que efetivamente existe (BRASIL, 2012, p. 19). O voto do relator entende que a regulamentação do dispositivo constitucional, é uma questão jurídica, a ser resolvida no âmbito da legislação vigente.

De onde vem a convicção acerca da caracterização legalmente válida do que seriam os quilombolas? Aqui, o relator mostra total concordância com os argumentos da Petição do PFL. Os destinatários do direito conferido pelo artigo 68 do ADCT seriam:

(...) aqueles que subsistiam nos locais tradicionalmente conhecidos como quilombos, entendidos estes na acepção histórica, em 05 de outubro de 1988. Noutras palavras: os que, tendo buscado abrigo nesses locais (quilombos), antes ou logo após a abolição, lá permaneceram até a promulgação da Constituição de 1988 (BRASIL, 2012, p. 38).

A conviçção do ministro, deriva de uma interpretação. A categoria quilombo adequada para a regulamentação do Artigo 68 seria de fundo cronológico e, portanto, os sujeitos do direito garantido pela Constituição seriam remanescentes de eventos que deveriam ter ocorrido até o período imperial. Mas por que, segundo o relator, a concepção cronológica do quilombo seria a jurídica em oposição à metajurídica, presente no Decreto? A resposta seria simples. A definição com a qual a legislação deve operar é aquela que tinha validade quando da composição da Constituição. Apesar do termo quilombo poder carregar diversos sentidos, deveria ser considerada juridicamente válida a "acepção histórica, que é conhecida de toda a gente" (BRASIL, 2012, p. 39) e que se encontra no dicionário da língua portuguesa.

O ministro segue afirmando que os estudos de antropólogos e de juristas que pretendem "ampliar e modernizar o conceito de quilombos" (BRASIL, 2012, p.39), não têm relação com o sentido do texto constitucional. Do ponto de vista jurídico e referido ao dispositivo constitucional, somente "certa categoria de pessoas" seriam abarcadas pelos efeitos do Artigo 68 do ADCT (BRASIL, 2012, p. 39). 


\section{3 - O voto da ministra Rosa Weber}

Após o voto do relator, o julgamento foi suspenso por um pedido de vistas e somente retornou a pauta do SFT em 25 de março de 2015. Rosa Weber, apesar de considerar a ADI admissível para julgamento, propõe que a ação é improcedente na declaração de inconstitucionalidade do Decreto $n^{\circ} 4.887 / 2003$. A partir deste ponto, passa a construir suas argumentações com base nas alegações propostas pela Petição do PFL.

O primeiro ponto diz respeito à validade ou não do uso de Decreto para regulamentação daquela matéria constitucional específica. O entendimento da ministra é de que o artigo 68 do ADCT tem um objeto claro: o direito dos quilombolas ao reconhecimento das terras por eles ocupadas. Isto leva a ministra a apontar que se trata de: "Uma norma definidora de direito fundamental de grupo étnico-racial minoritário, dotada, portanto, de eficácia plena e aplicação imediata, e assim exercitável, o direito subjetivo nela assegurado, independentemente de integração legislativa" (BRASIL, 2015, p. 14).

A ministra concorda que o Decreto regulamenta diretamente o artigo 68 do ADCT, mas aponta que este é o procedimento correto, uma vez que tal artigo se refere a direito fundamental, que exige regulamentação imediata, e carrega elementos de auto aplicação. O voto decompõe o artigo 68 em dois enunciados: o primeiro indica um "direito fundamental" baseado em um "direito de propriedade qualificado ("aos remanescentes das comunidades dos quilombos(...) é reconhecida a propriedade definitiva"). O segundo, constitui uma determinação para que o Estado realize uma ação necessária para que o direito antes descrito, possa ser acessado ("deve o Estado emitir-lhes os títulos respectivos") (BRASIL, 2015, p. 15).

O primeiro enunciado, não estaria prevendo a existência de um direito a ser exercido no futuro. Sua interpretação é que o "direito fundamental subjetivo está consagrado no próprio preceito constitucional transitório" (BRASIL, 2015, p. 15). Esta argumentação pressupõe o entendimento de que o artigo 68 do ADCT equivale a uma norma constitucional de eficácia plena $^{5}$, que não demanda ação legislativa. Ao contrário, limita a ação legislativa, pois garante que nenhuma lei criada no futuro pode cercear os direitos anteriormente previstos. $\mathrm{O}$ artigo 68 do ADCT seria definidor de um direito fundamental, na medida em que remete à direito de propriedade (em consonância com o artigo $5^{\circ}$ da Constituição de 1988). Quando se trata de regra constitucional que remete a este tipo de direito, é necessário compreendê-la no sentido da maior eficácia possível. Portanto, não

\footnotetext{
5 Uma norma constitucional de eficácia plena possui aplicação imediata, não depende de legislação posterior e não pode ter seus efeitos limitados a posteriori. Já uma norma constitucional de eficácia limitada não possui aplicação imediata e somente fica garantido o direito ou vínculo ao qual se refere, após aprovação de legislação que a regulamente. (SILVA, 1998).
} 
seria legitima uma interpretação de texto constitucional que engendra direito fundamental, que pudesse levar a inexistência do sujeito deste, tornando vazio de sentido o dispositivo.

Já o segundo enunciado define que o Estado deve emitir os títulos de propriedade que se originam do direito fundamental definido. Para isto a gestão pública precisa estabelecer normatizações específicas. Assim, não somente estaria justificada a emissão do Decreto, como esta seria necessária. Ao mesmo tempo, seria impossível dar cumprimento a norma constitucional, sem algum grau de interpretação. Rosa Weber, neste ponto é taxativa: "todo e qualquer ato jurídico, enquanto ato linguístico, é - ou resulta de -, em última análise, um ato de interpretação" (BRASIL, 2015, p. 19).

Nesta direção, o voto não identifica no Decreto uma violação do artigo $\mathrm{n}^{\circ}$ 84 da Constituição de 1988. Ao contrário, tratar-se-ia de uma regulação da ação do Estado para dar cumprimento ao comando constitucional. Com isto, a ministra conclui não haver indício de inconstitucionalidade formal no Decreto e passa a discutir os pedidos de declaração de inconstitucionalidade material.

Para Rosa Weber o debate em curso corresponde a responder a seguinte pergunta: a "exegese do art. 68 do ADCT empreendida pela administração se adequada ou não ao real conteúdo do texto constitucional”? (BRASIL, 2015, p. 21). Qual o parâmetro juridicamente adequado para responder a esta pergunta? Seria a "realização do conteúdo do comando constitucional" (BRASIL, 2015, p. 21). O que se impõe no caso de dispositivo referido a um direito fundamental. Isto porque, quando tal direito é reconhecido na Lei Maior, o impedimento ou inviabilidade de seu exercício (por ação deliberada, ou por omissão) seria - isso sim - inconstitucional.

Construído este pano de fundo, o voto passa a argumentar que o formato interpretativo presente no Decreto $n^{\circ} 4.887 / 2003$ não é inconstitucional. Nesta direção, o primeiro ponto discutido é o critério de autoatribuição. Para o enfrentamento deste debate, a ministra produz uma descrição dos "chamados quilombolas" (BRASIL, 2015, p. 22). Estes seriam "povos tradicionais" que apesar de não serem nativos (como os indígenas), também carregam "traços étnico-culturais distintivos marcados por especial relacionamento sociocultural com a terra ocupada" (BRASIL, 2015, p. 22). Vemos no trecho acima citado, o uso de três categorias produzidas no âmbito da antropologia no contexto da questão quilombola. Primeiro a categoria povos tradicionais, acompanhada da categoria etnicidade e em seguida de território. De fato, a partir deste ponto em que o voto começa a debater os elementos materiais do Decreto, o recurso à lógica discursiva externa ao campo do direito é mais presente.

O voto segue investindo na explicitação dos formatos que podem ser admitidos para as comunidades quilombolas. Assim, se refere aos casos de comunidades 
formadas a partir da doação de terras a libertos, feitas por seus próprios ex-proprietários. Exatamente por isso seria "falacioso" pretender demarcar um sentido "puro" (BRASIL, 2015, p. 31) para o conceito de quilombo; da mesma forma que não existiria um significado que poderíamos atribuir ao constituinte, ou mesmo intuir o que este havia utilizado quando da redação do texto constitucional. Assim, a interpretação realizada pela administração pública para operacionalizar o comando constitucional implica em definir um sentido para quilombo, que será juridicamente válido se for adequado "às balizas linguísticas e hermenêuticas impostas pelo texto-norma do art. 68 do ADCT" (BRASIL, 2015, p. 31).

Apoiando-se em Fraser (2006) aponta que a Constituição de 1988 garantiu aos quilombolas os dois elementos que seriam pilares da justiça social no mundo contemporâneo: a redistribuição (através da propriedade de suas terras) e o reconhecimento (através da valorização e aceitação da identidade do grupo). Segundo a ministra, nos quadros da Constituição, que seria comprometida com a justiça social e com a redução das desigualdades (o que está expresso no artigo $3^{\circ}$, I e III), a interpretação dos dispositivos legais que emanam desta, devem dar respostas tanto aos aspectos relativos a pobreza, quanto ao "desrespeito cultural" (BRASIL, 2015, p. 33).

Tais respostas devem ser complementares, como aponta Fraser (2006) e incorporar tanto, remédios voltados para desfazer a pobreza econômica, quanto aqueles que combatam o preconceito cultural. Exatamente por isso estaria justificado o uso do critério de autoatribuição, tal como aparece no Decreto ${ }^{\circ} 4.887 / 2003$. Trata-se de interromper um processo histórico em que a sociedade nega a identidade de "grupos marginalizados" (BRASIL, 2015, p. 33).

O próximo ponto debatido no voto se refere ao pedido de declaração da inconstitucionalidade do Decreto, pela forma como este define o que seriam as "terras" dos "quilombolas" que deveriam ser alvo de titulação. Novamente, Rosa Weber se opõe à demanda da ADI n 3.239/2004 e assevera que não tem fundamento a afirmação encontrada na Petição Inicial da ação, de que a demarcação atenderia a critérios dos próprios interessados. Pois, a forma de ocupação da terra que estes grupos quilombolas desenvolveram corresponde a uma matriz tradicional, semelhante a existente entre os indígenas. De fato, Rosa Weber está lançando mão, neste ponto do debate, da categoria território que é largamente utilizada no campo da antropologia nacional. Não por acaso, para definir o que seriam as áreas ocupadas pelos remanescentes a ministra usa texto da antropóloga Lucia Andrade (1994). Estas corresponderiam "às terras utilizadas por aquele grupo social para garantir sua sobrevivência, ou mais ainda, para assegurar a reprodução de seu modo de vida específico" (ANDRADE, 1994 apud BRASIL, 2015, p. 41). Por respeitar estas características da "relação territorial" desenvolvida pelas comunidades, é que o Decreto não se refere à titulação individual, mas sim, 
a uma "unidade sociocultural" - daí a titulação coletiva e pró-indiviso (BRASIL, 2015, p. 42).

A ministra afirma ainda que a Convenção 169 da Organização Internacional do Trabalho (OIT), em especial em seu artigo $6^{\circ}$, dá sustentação ao formato proposto no Decreto $\mathrm{n}^{\circ} 4.887 / 2003$, na medida em que indica a necessidade de consulta aos povos interessados quando forem realizadas ações que possam lhes atingir. No contexto do Decreto em análise, o que estaria proposto seria a garantia da participação das comunidades "nos procedimentos necessários à determinação das terras por eles ocupadas" (BRASIL, 2015, p. 43), e não a submissão da demarcação a determinações das comunidades. Isto porque, segundo a ministra é evidente que as terras a serem tituladas são aquelas que estavam sob "ocupação tradicional" até 05 de outubro de 1988. Ou seja, a garantia do direito territorial para os quilombolas, não deriva somente da autodefinição da comunidade, mas também da evidência de ocupação tradicional e histórica.

Reaparece neste ponto da argumentação o recurso a uma definição cronológica de quilombo. Esta submissão à cronologia seria derivada do artigo 68 do ADCT, na medida em que: a) este nomeia como titulares do direito aqueles que estejam ocupando suas terras e; b) a incidência do comando constitucional prende-se à data da promulgação da Lei Maior. Assim, segundo o voto, não estariam cobertas pelo Decreto comunidades que (mesmo se auto identificando como quilombolas), não estavam mais integradas em 05 de outubro de 1988, ou que nesta data ainda não existiam e somente a posteriore passaram a ocupar terras que teriam pertencido a seus antepassados. Somente seria possível admitir a flexibilização desta regra, em caso de "turbação ou esbulho" (BRASIL, 2015, p. 44), ou seja, no caso de comunidades que não estivessem ocupando suas terras nesta data, por terem sido ilegalmente expulsas ou impedidas de continuar a ocupação.

Também há outra conexão, segundo Rosa Weber, que não pode ser esquecida; aquela existente entre o artigo 68 do ADCT e os artigos 215 e 216 da Constituição. Disto decorreria, que não somente está autorizada a desapropriação dos títulos privados incidentes sobre territórios quilombolas, como esta é mesmo exigida para a garantia de fruição de direito fundamental por seus titulares. Enfim, o voto de Rosa Weber, opta por tomar a ADI n ${ }^{\circ} 3.239 / 2004$ como admissível para julgamento, no entanto, julga a mesma improcedente. 


\section{5 - Considerações finais}

No dia 8 de fevereiro de $2018^{6}$ o julgamento da ADI $n^{\circ} 3239 / 2004$ chegou ao fim. O desfecho final desse embate foi desenhado com um placar de oito votos favoráveis ao direito territorial dos quilombolas - dos ministros Rosa Weber, Edson Fachin, Luís Roberto Barroso, Ricardo Lewandowski, Luiz Fux, Marco Aurélio, Celso de Mello e Cármen Lúcia, e três votos contrários. Durante o julgamento as discussões foram posicionadas principalmente para a questão do marco temporal defendida pelo DEM e bancada ruralista durante todo o processo da ADI, além de considerações sobre a autodeclaração como um critério para o reconhecimento de comunidades quilombolas.

Interessante notar que durante o julgamento, interpretações antropológicas, como os estudos de Alfredo Wagner (1989) foram citados acatando a manifestação da Procuradoria Geral da União que havia se manifestado favoravelmente sobre o direito à titulação territorial das comunidades quilombolas há anos atrás, nos autos do processo, principalmente no que diz respeito à autoatribuição e etnogenese. Além disso, os ministros que se posicionaram contra a ADI entenderam ser legítima a possibilidade de desapropriação pela Administração para a aquisição de terras particulares onde se localizem comunidades remanescentes de quilombos, já que o Decreto $n^{\circ} 4887 / 2003$ prevê justa indenização.

Outro ponto em comum durante o julgamento foi a concordância entre os oito ministros de que o acesso à titulação territorial se trata de direito fundamental que deve ser garantido aos grupos quilombolas. Considerou-se ainda que a questão indígena tem sua aplicação de forma complexa e conflituosa, mas que a questão quilombola se mostra ainda mais grave por se tratar de um grupo que até o Artigo 68 do ADCT permanecia invisibilizado e começa a ganhar pauta recentemente frente a agenda pública.

Neste sentido, foi relembrada também a diversidade de posses existentes no Brasil desde a lei de terras, quando pensamos na realidade das comunidades negras rurais e urbanas do país. Citou-se também o dever do Estado de garantir e proteger o direito destes povos a titulação territorial lembrando que estes são resguardados mundialmente pela Convenção 169 da OIT. Por fim, o julgamento proferido pelos ministros do STF conclui que é dever do campo do direito proteger o direito das minorias fortalecendo assim o regime democrático. Ao final foi enunciado o resultado: a ADI foi reconhecida, interpretada e julgada como improcedente, ficando o Decreto $n^{\circ} 4887 / 2004$ mantido.

\footnotetext{
6 Importante ressaltar que o Acordão deste importante julgamento ainda não foi publicado para maiores análises neste artigo.
} 
Assim, o campo do direito foi chamado para essa arena ao possuir a legitimidade institucional, para dar a resposta final à pergunta central: quem tem direito ao direito instituído pelo artigo 68 do ADCT? A chamada ciência jurídica projeta uma imagem do direito como um longo caminho de construção de conceitos e métodos que, autonomamente, seriam definidos pelos componentes do campo, de forma livre (BOURDIEU, 2003). Em polo oposto a este, a crítica da autonomia do jurídico aponta que as proposições oriundas deste campo seriam "um reflexo direto das relações de força existentes, em que se exprimem as determinações econômicas (...)" (BOURDIEU, 2003, p. 210).

O ponto de vista no qual nos colocamos não caminha em nenhuma destas duas direções. Tomamos o campo do direito como o locus de construção da autoridade jurídica - que nas sociedades ocidentais ganhou a legitimidade social para monopolizar a capacidade de definir qual é a última palavra sobre um litígio. Como qualquer campo, este também guarda uma relativa autonomia, ancorada não em suposta neutralidade, mas sim na existência de uma lógica interna que sustenta suas discursividades. Essa lógica interna se veste com a toga da imparcialidade, na medida em que os julgamentos emitidos são o produto da ação de um corpo especializado de profissionais, legitimados socialmente, que codificam os conflitos entre partes em litígio e oferecem soluções a partir do uso de um corpus acumulado de regras e procedimentos. Este corpus é apresentado como independente do que está em debate naquele momento específico.

Neste ponto, se encontra a magia que sustenta a pretensão de imparcialidade. O debate no campo do direito não se faz através das discursividades dos litigantes, mas sim de uma antiga e consolidada discursividade dos profissionais socialmente autorizados a atuar neste campo. Por isso, Bourdieu (2003) se refere a um processo de codificação dos conflitos, que resulta na emissão do juízo legitimado socialmente como imparcial, emitido sob o signo de uma discursividade hermética e exógena em relação aqueles que estão perguntando: quem tem direito? Trata-se de um poder simbólico de amplas proporções, com efeitos objetivos de largo alcance, que somente é eficaz por ser reconhecido socialmente como legitimo e, ao mesmo tempo, porque consegue manter desconhecido o quanto de arbitrário está presente nos seus discursos, ao turvá-los com a névoa de uma alegada imparcialidade.

Não podemos esquecer, porém, que nas lutas que se desenvolvem no campo do direito, parte dos agentes procura inserir novas categorias no baú de significados que podem ser manuseados para a emissão da discursividade socialmente legitimada. Neste caso específico que estamos analisando, estas categorias foram buscadas no discurso antropológico. 


\section{THE QUILOMBOLA QUESTION AND THE FIELD OF LAW}

ABSTRACT: Brazil has been setting up the issue of the quilombola since 1988, through different assemblages that culminated in article 68 of the Transitional Constitutional Provisions Act which guaranteed this group's right to land ownership. However, from that point forward, complex modes of interpretation of the regulations of the constitutional text appeared. In this article we seized on the notion of "field" as it is defined by Bourdieu, in order to discuss the inclusion of the law in the complex discursive dispute about the socially legitimate definition of what quilombolas are. We approached this debate through litigation in the jurisdiction of the Federal Supreme Court about the validity of concepts and characterizations of what constitute quilombolas and their territories as our main focus.

KEYWORDS: Quilombola communities. Field of law. Supreme Federal Court.

\section{LA CUESTIÓN QUILOMBOLA Y EL CAMPO DEL DERECHO}

RESUMEN: La cuestión quilombola se viene constituyendo desde 1988 en Brasil a partir de los requerimientos que culminaron en el artículo 68 del Acto de las Disposiciones Constitucionales Transitorias. Por medio de este dispositivo quedó garantizado el derecho a la propiedad de la tierra para este grupo. Pero a partir de este punto se abren complejas posibilidades de interpretación que se dirigen a la reglamentación del texto constitucional. En este artículo nos apropiamos de la noción de "campo", tal como se define en la obra de Bourdieu, para pensar la inserción del derecho en la compleja disputa discursiva en torno a la definición socialmente legitima de lo que serían los quilombolas. En este debate, tomamos como enfoque principal el litigio en el ámbito del Supremo Tribunal Federal, acerca de la validez de conceptos y caracterizaciones sobre lo que serían los quilombolas y sus territorios.

PALABRAS CLAVE: Comunidades quilombolas. Campo del derecho. Supremo Tribunal Federal.

\section{REFERÊNCIAS}

ABA - ASSOCIAÇÃO BRASILEIRA DE ANTROPOLOGIA. Documento do grupo de trabalho sobre comunidades negras rurais. Rio de Janeiro: 1994,

ALMEIDA, Alfredo Wagner Berno de. Terras de preto, terras de santo, terras de índio: uso comum e conflito. Belém: NAEA/UFPA, 1989. 
ANDRADE, Lucia. O Papel da Perícia Antropológica no Reconhecimento das Terras de Ocupação Tradicional - O Caso das Comunidades Remanescentes de Quilombos do Trombetas (Pará). In: SILVA, Orlando Sampaio; LUZ, Lídia e HELM, Cecília M. Vieira. A Perícia Antropológica em Processos Judiciais. Florianópolis: Editora da UFSC, 1994.

ANJOS, José Carlos Gomes dos. Remanescentes de quilombos: reflexões epistemológicas. In: LEITE, Ilka Boaventura (Org). Laudos periciais antropológicos em debate. Florianópolis: Co-edição NUER/ABA, 2005.

ARRUTI, José Maurício. Mocambo: antropologia e história do processo de formação quilombola. São Paulo: Edusc, 2006.

BARTH, Fredrik. Os grupos étnicos e suas fronteiras. In: BARTH, Fredrik. O guru, o iniciador e outras variações antropológicas. Rio de Janeiro: Contra Capa Livraria, 2000.

BOURDIEU, Pierre. O poder simbólico. Rio de Janeiro, Bertrand Brasil, 2003.

BOURDIEU, Pierre \& WACQUANT, Loic. Responses: pour une antropologie reflexive. Paris: Seuil, 1992.

BRASIL. Câmara dos Deputados. DECRETO No 3.912, DE 10 DE SETEMBRO DE 2001. Disponível em: $<$ http://www2.camara.leg.br/legin/fed/decret/2001/decreto-3912-10setembro-2001-395404-norma-pe.html>. Acessado em: 22 nov. 2018.

BRASIL. Presidência da República-Casa Civil. Decreto $N^{0} 4.887$ de 20 de novembro de 2003. Brasília-DF, 2003. Disponível em: $<$ http://www.planalto.gov.br/ccivil_03/ Decreto/2003/D4887.htm>. Acessado em: 22 nov. 2018.

BRASIL. Supremo Tribunal Federal (STF). Ação Direta de Inconstitucionalidade. Brasília, 25 de junho de 2004. Disponível em: <http://redir.stf.jus.br/paginador/paginador. jsp?docTP=TP\&docID=394738>. Acessado em 22 nov. 2018.

BRASIL. Supremo Tribunal Federal. Voto do relator Ministro Cezar Peluso (voto do relator, 2012). Ação Direta de Inconstitucionalidade no 3.239 DF. Plenário, 18 de abril de 2012. Disponível em: <http://www.sbdp.org.br/arquivos/material/1459_ADI3239_Voto. pdf $>$. Acessado em: 07 dez. 2015.

BRASIL. Supremo Tribunal Federal. Voto vista 2015 - Ministra Rosa Weber. Ação Direta de Inconstitucionalidade no 3.239 DF. Plenário, 25 de março de 2015. Disponível em: <http:// www.stf.jus.br/arquivo/cms/noticiaNoticiaStf/anexo/ADI3239RW.pdf>. Acessado em: 07 dez. 2015.

BRASIL. MPF. Resumo do Julgamento da ADI 3239 - dia 8 de fevereiro de 2018. Disponível em: $<$ https://www.google.com.br/search?q=Resumo + do + Julgamento + da + A DI+3239>. Acessado em: 02 nov. 2018. 
FIGUEIREDO, André Luiz Videira de. O caminho quilombola: interpretação constitucional e reconhecimento de direitos étnicos. Rio de Janeiro: UCAM/IUPERJ, 2008. Tese de Doutorado - Universidade Candido Mendes, Instituto Universitário de Pesquisa do Rio de Janeiro.

FRASER, Nancy. Da redistribuição ao reconhecimento? Dilemas da justiça numa era "póssocialista”. Cadernos de Campo, v.15, n. 14/15, p 231-239, 2006.

FRASER, Nancy. Repensando o reconhecimento. Revista Enfoques. UFRJ, Rio de Janeiro, V.9, n. 1, p. 114-128, agosto 2010.

HONNETH, Axel. Reconhecimento ou redistribuição? A mudança da perspectiva na ordem moral da sociedade. In: SOUZA, J. e MATTOS, Patrícia (orgs.). Teoria crítica do século XXI. São Paulo: Anablume, 2007.

O'DWYER, Eliane Cantarino. Os quilombos e a prática profissional dos antropólogos. In: (Org). Quilombos: identidade étnica e territorialidade. Rio de Janeiro: Editora da FGV, 2002.

OLIVEIRA, Frederico Menino Bindi de. Mobilizando oportunidade: estado, ação coletiva e o recente movimento social quilombola. São Paulo: Universidade de São Paulo, 2009. Dissertação de Mestrado.

SILVA, José Afonso da. Aplicabilidade das Normas Constitucionais. São Paulo, Malheiros, 1998.

TAYLOR, Charles et al. Multiculturalismo: examinando a política de reconhecimento. Princenton University Press, 1994.

WEBER, Max. Os tipos de dominação. In: WEBER, Max. Economia e Sociedade. Volume 2. Brasília: UNB, 1994.

Recebido em 28/07/2018.

Aprovado em 09/11/2018. 